Hussain A Obaidi

BDS, MSc (Prof)

Manar Y Abdul-Qadir

BDS, MSc (Assist Lect)

\section{Soft Tissue Nasal Profile Changes}

\author{
Dept of Pedod, orthod, and Prev Dentistry \\ College of Dentistry, University of Mosul \\ Dept of Pedod, orthod, and Prev Dentistry \\ College of Dentistry, University of Mosul
}

\begin{abstract}
Aims: To reveal the changes of the soft tissue profile of the nose, that include; length, height and depth of the nose among four age groups. Materials and Methods: The studying sample subjects included 48, 41, 50 and 44 individuals of age 11, 12,13 and 14 years respectively. The subjects were Iraqi individuals of class I normal occlusion, who live in center of Mosul City. All subjects were radiographed with the lateral cephalometric films, these films were traced and drawing the linear parameters of the nose, the tracing involve the length $\left(\mathrm{N}^{`}-\mathrm{Prn}\right)$, width $(\mathrm{N}-\mathrm{Sn})$ and depth (Prn - Prn '). The results were subjected to the descriptive and variance analyses. Results: The results appeared in males the length of the nose increase in dimension with no significant differences when compared among the four age groups, whereas in females showed significant increase when compared the 11, 12 years with 13 years and with 14 years age groups. While, the $\mathrm{h}$ weight of the nose $\left(\mathrm{N}^{`}-\mathrm{Sn}\right)$ appeared in males and females significantly increase at 14 years age group when compared with other age groups. But significantly increased at 12 years age group as compared with 11 years age group, in males only. Mean while, the depth of the nose (Prn - Prn') displayed significantly increase at age 14 years group when compared with 11 and 12 years age groups for both sexes. The comparison between sexes for the nose parameters demonstrated that the length, width and depth of the nose displayed significantly increase in males than females at 11 years age group and no significantly differences at other age groups. Conclusions: The conclusions of the study are that the nose have significantly increase between 11 and 14 years age group in both sexes, the nasal profile parameters have insignificant difference in dimensions among 12, 13 and 14 years age groups.

Key words: Nasal profile, nasal length, height and depth.
\end{abstract}

Obaidi HA, Abdul - Qadir MY. Soft Tissue Nasal Profile Changes. Al-Rafidain Dent J. 2007; 7(2): 24S-29S.

Received: 3/4/2006 Sent to Referees: 5/6/2006

Accepted for Publication: 26/11/2006

\section{INTRODUCTION}

The nasal features categorize into; Leptorrhine (long, high and narrow nose), Mesorrhine (dorsal and alar widenes of the nose) and Platyrrhine (flat, broad nose and wide nostrils) ${ }^{(1)}$. The nose dominates the midface on profile, it's size and projection must be considered in the cortext of the lip and chin projection ${ }^{(2)}$. The form and position of the midface soft tissue appear to be less dependent on underlying hard tissue than for lower facial soft tissue ${ }^{(3)}$.Soft tissue values are important as hard tissue values, the nose height and prominence increase with an average annual increase of $2 \mathrm{~mm}$ between 5 and 10 years of age ${ }^{(4)}$. Nasal projection in females remained constant from ages 12 to 17 years with greater growth rate resulting in a slightly greater degree of nasal prominence in male at age 17 years ${ }^{(5)}$.

Authors ${ }^{(6)}$ reported a forward growth of nasal tip with average of $8 \mathrm{~mm}$ in late adolescent male. The rate of growth for the vertical length and depth of the nose are twice that of the rate on increase for horizontal width of nose during adolescence (7). The nose continues to grow in downward and forward direction during adulthood $^{(8,9)}$. The nose increased in all dimensions in both males and females ${ }^{(10)}$.

The aim of this study was to reveal the changes of the soft tissue profile of the nose that include; length, height and depth of the nose among four age groups for Iraqi individuals who live in center of Mosul City. 


\section{MATERIALS AND METHODS}

The sample was selected from 20 intermediate schools (11 for girls and 9 for boys) and 16 primary schools (8 for girls and 8 for boys) in the center of Mosul City. The criteria for the sample selected were: Full complement of permanent teeth excluding the third molars, normal occlusion class I molar and canine relationship (11), normal overjet and overbite (1-4 mm) ${ }^{(12)}$, no detectable crowding and rotation and spacing ${ }^{(13)}$, no apparent facial disharmony, no previous orthodontic treatment or maxillofacial surgery. The sample subjects met the selection criteria was divided according to age into four groups;

11 years age group (23 males and 25 females).

12 years age group (19 males and 22 females).

13 years age group (22 males and 28 females).

14 years age group (22 males and 22 females).

Each subject was radiographed with lateral cephalometric film in the Radiology
Center in the Dental School, University of Mosul, with standardized manner for all the individuals according to Radiology Center instructions.

The lateral cephalometric radiographs of the sample subjects were traced, the tracing included; the length of the nose $\left(\mathrm{N}^{\prime}-\mathrm{Prn}\right)$ as measured from soft tissue nasion $\left(\mathrm{N}^{\prime}\right)$ to the tip of the nose pronasal (Prn), and the height of the nose ( $\left.{ }^{`}-\mathrm{Sn}\right)$ as measured from soft tissue nasion to soft tissue subnasal point $(\mathrm{Sn}){ }^{(14)}$, and the depth of the nose (Prn - Prn') as measured from the tip of the nose to the point of intersection of a line drawn parallel to the pterygomandibular vertical (PMV) plane from soft tissue nasion (projected prenasal Prn') with a line drawn perpendicular to the PMV plane through (Prn') ${ }^{(12)}$, (Figure $1)$.

The results were subjected to the descriptive and variance analysis at $p \leq 0.05$, to reveal the variances among the four age groups and to explore the sex variation for each of nasal profile parameter.

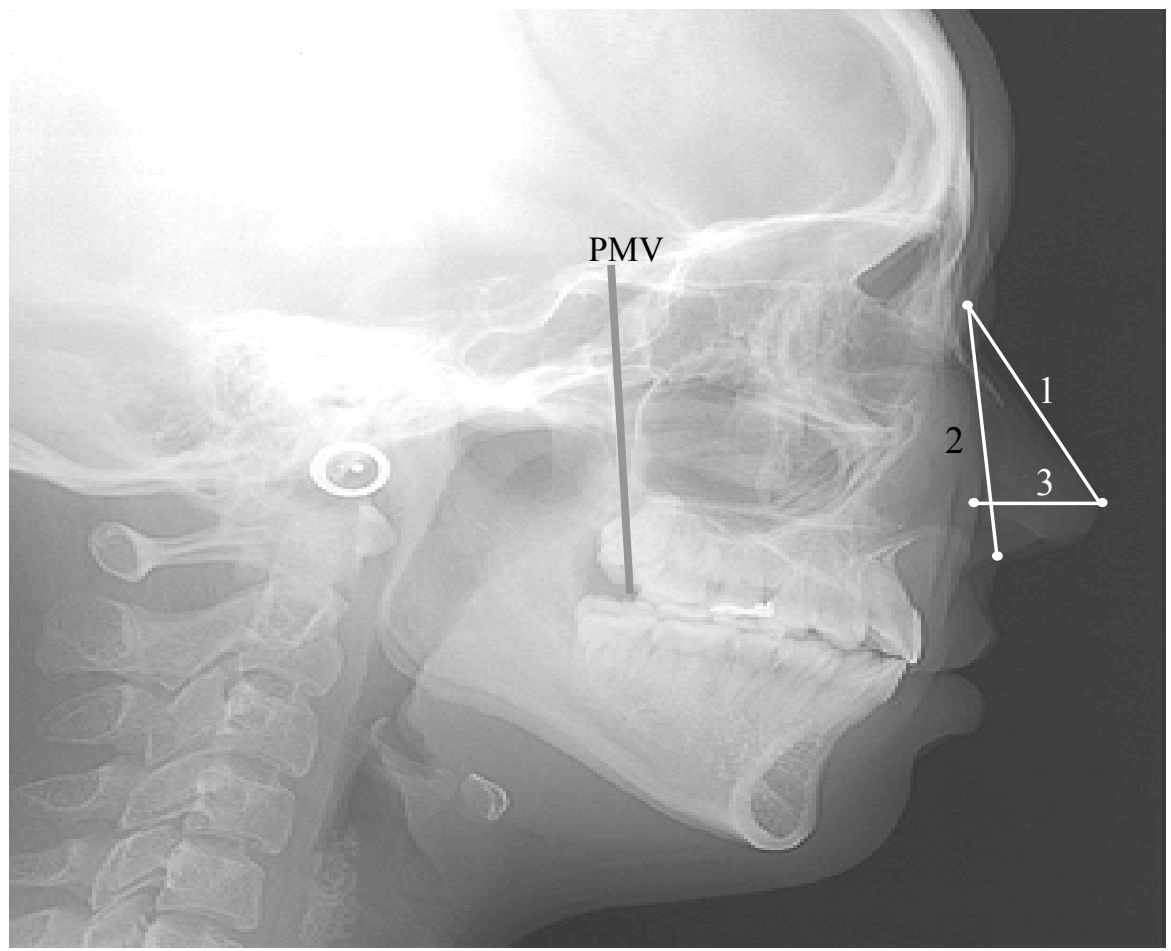

Figure (1): Soft tissue linear measurements.

1. N-Prn. 2. N-Sn 3. Prn - Prn. ; (PMV): Pterygo-Maxillary vertical plane. 


\section{RESULTS}

The descriptive statistics, Table (1) showed that the nasal parameters $\left(\mathrm{N}^{\prime}-\mathrm{Prn}\right.$, $\mathrm{N}$ `- Sn, Prn - Prn') were highest mean values at 14 years age group for the both sexes.

In males, Table (2, 3 and 4), the comparison between 11 years and 12 years groups revealed higher value at 12 years group with no significance for all nasal parameters except (N`- Prn) which showed significantly higher value at 12 years group, and in comparison between 12 years and 13 years groups revealed higher mean value at 13 years with no signifycance for the all nasal parameters, whereas in comparison between 13 years and 14 years groups demonstrated higher values at 14 years with no significant with nasal parameter (Prn - Prn '). (N` - Prn) and (N` - Sn) parameters displayed significantly higher values at 14 years group than 13 years group. At 14 years group the nasal parameters $\left(\mathrm{N}^{`}-\mathrm{Prn}\right),\left(\mathrm{N}^{`}-\mathrm{Sn}\right)$ and $(\mathrm{Prn}-$ Prn') showed significantly higher values as compared to 11 years group, but the (Prn - Prn), ( N - Prn), ( $\left.{ }^{`}-\mathrm{Sn}\right)$ and (Prn - Prn') showed significantly higher values at 14 years than 12 years group.

In females, the comparison between 11 years and 12 years groups all the nasal parameters showed a higher value at 12 years group, all these differences failed to reach significant level, and in comparison between 12 years and 13 years groups revealed higher mean value at 13 years with no significance for the all nasal parameters, also in comparison between 13 years and 14 years groups displayed higher values at 14 years for all nasal parameters, and all these differences where not statistically significant, whereas in comparison between 11 years and 14 years groups displayed significantly higher values at 14 years group for all the nasal parameters. The only significant difference noticed between 14 years group and 12 years group was for (Prn - Prn') which showed higher value at 14 years group.

Table (1): Descriptive statistics for the soft tissue variables of males and females of four age groups.

\begin{tabular}{|c|c|c|c|c|c|c|c|}
\hline Age group & Variable & Examination & Number & Minimum & Maximum & Mean & $\pm \mathrm{SD}$ \\
\hline \multirow{6}{*}{$\begin{array}{l}\stackrel{\infty}{\vec{\Xi}} \\
\stackrel{\Xi}{\beth}\end{array}$} & \multirow{2}{*}{$\mathbf{N}^{`}-\operatorname{Prn}$} & Male & 23 & 42 & 55 & 47.43 & 3.80 \\
\hline & & Female & 25 & 45.5 & 54 & 49.38 & 2.50 \\
\hline & \multirow{2}{*}{$N^{`}-S n$} & Male & 23 & 49 & 61 & 54.74 & 3.15 \\
\hline & & Female & 25 & 52 & 62 & 56.38 & 2.48 \\
\hline & \multirow{2}{*}{ Prn - Prn` } & Male & 23 & 22.5 & 30 & 25.35 & 2.17 \\
\hline & & Female & 25 & 19.5 & 30 & 25.94 & 2.56 \\
\hline \multirow{6}{*}{ 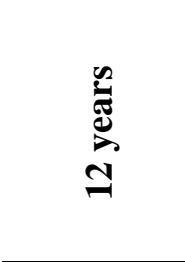 } & \multirow{2}{*}{$\mathbf{N}^{`}-\mathbf{P r n}$} & Male & 19 & 44 & 53 & 47.76 & 3.23 \\
\hline & & Female & 22 & 42 & 60 & 50.07 & 4.23 \\
\hline & \multirow{2}{*}{$\mathbf{N}^{`}-\mathbf{S n}$} & Male & 19 & 51 & 60 & 55.29 & 2.58 \\
\hline & & Female & 22 & 49 & 62 & 56.86 & 3.41 \\
\hline & \multirow{2}{*}{ Prn - Prn` } & Male & 19 & 21 & 30 & 25.71 & 2.58 \\
\hline & & Female & 22 & 23 & 32 & 26.77 & 2.48 \\
\hline \multirow{6}{*}{ 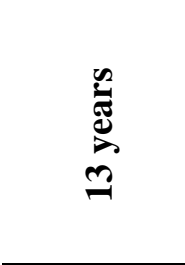 } & \multirow{2}{*}{$\mathbf{N}^{`}-\mathbf{P r n}$} & Male & 22 & 43 & 57 & 50.70 & 3.38 \\
\hline & & Female & 28 & 42 & 55 & 50.64 & 3.04 \\
\hline & \multirow{2}{*}{$N^{`}-\mathbf{S n}$} & Male & 22 & 51.5 & 64 & 57.80 & 3.10 \\
\hline & & Female & 28 & 51 & 62 & 57.59 & 2.68 \\
\hline & \multirow{2}{*}{ Prn - Prn } & Male & 22 & 22 & 33 & 27.27 & 2.98 \\
\hline & & Female & 28 & 24 & 30 & 27.57 & 1.57 \\
\hline \multirow{6}{*}{ 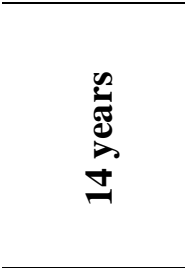 } & \multirow{2}{*}{$\mathbf{N}^{\prime}-\operatorname{Prn}$} & Male & 22 & 48 & 64 & 54.64 & 4.03 \\
\hline & & Female & 22 & 45 & 62 & 52.91 & 4.42 \\
\hline & \multirow{2}{*}{$\mathbf{N}^{`}-\mathbf{S n}$} & Male & 22 & 55 & 71 & 61.57 & 3.63 \\
\hline & & Female & 22 & 52 & 69 & 59.27 & 4.91 \\
\hline & \multirow{2}{*}{ Prn - Prn } & Male & 22 & 23 & 36 & 29.23 & 3.44 \\
\hline & & Female & 22 & 21 & 33 & 29.25 & 2.75 \\
\hline
\end{tabular}

All measurements in $\mathrm{mm}$ 
In comparison between males and females appeared that at 11 years group females higher value than males with no significant difference for (Prn - Prn'), also showed significantly higher value than males for $\left(\mathrm{N}^{\prime}-\mathrm{Prn}\right)$ and $\left(\mathrm{N}^{\prime}-\mathrm{Sn}\right)$. While, at 12 years group females demonstrated higher values than males with no significance difference for the all nasal parameters and at 13 years group the parameters $\left(\mathrm{N}^{`}-\mathrm{Prn}\right)$ and $\left(\mathrm{N}^{`}-\mathrm{Sn}\right)$ revealed higher values in males than females but without significance difference, and females displayed higher value with no significant difference for (Prn - Prn') than males. Fourteen years group males demonstrated higher value than females with no significance difference for $\left(\mathrm{N}^{`}-\mathrm{Prn}\right)$ and $\left(\mathrm{N}^{\prime}-\right.$ Sn), whereas (Prn - Prn') showed higher value with no significance difference for females than males.

Table (2): Analysis of variance and Duncan's Multiple Range Test of $\mathrm{N}^{`}-\mathrm{Prn}$ variable for the four age groups.

\begin{tabular}{|c|c|c|c|c|c|}
\hline Sex & Age Group & Number & Mean & $+\mathrm{SD}$ & Duncan's Grouping* \\
\hline \multirow{4}{*}{$\frac{0}{\sum^{\pi}}$} & 11 Years & 23 & 47.435 & 3.797 & $\bar{A}$ \\
\hline & 12 Years & 19 & 47.763 & 3.229 & B \\
\hline & 13 Years & 22 & 50.705 & 3.383 & B \\
\hline & 14 Years & 22 & 54.636 & 4.030 & $\mathrm{C}$ \\
\hline \multirow{4}{*}{ 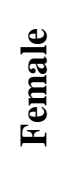 } & 11 Years & 25 & 49.380 & 2.497 & A \\
\hline & 12 Years & 22 & 50.068 & 4.232 & $\mathrm{AB}$ \\
\hline & 13 Years & 28 & 50.643 & 3.042 & $\mathrm{AB}$ \\
\hline & 14 Years & 22 & 52.909 & 4.423 & B \\
\hline
\end{tabular}

For males: $\mathrm{F}-$ value $=18.30 ; p$-value $=0.000 ; \mathrm{S}(p \leq 0.05)$. For females: $\mathrm{F}$-value $=4.17 ; p-$ value $=0.008 ; \mathrm{S}(p \leq 0.05)$ * Means with the same letters were statistically not significant.

Table (3): Analysis of variance and Duncan's Multiple Range Test of $\mathrm{N}^{\prime}-\mathrm{Sn}$ variable for the four age groups

\begin{tabular}{|c|c|c|c|c|c|}
\hline Sex & Age Group & Number & Mean & + SD & Duncan's Grouping* \\
\hline \multirow{4}{*}{$\frac{0}{\sum^{\pi}}$} & 11 Years & 23 & 54.739 & 3.151 & $\bar{A}$ \\
\hline & 12 Years & 19 & 55.289 & 2.578 & $\mathrm{AB}$ \\
\hline & 13 Years & 22 & 57.795 & 3.104 & B \\
\hline & 14 Years & 22 & 61.568 & 3.630 & $\mathrm{C}$ \\
\hline \multirow{4}{*}{ 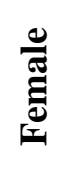 } & 11 Years & 25 & 56.380 & 2.476 & A \\
\hline & 12 Years & 22 & 56.864 & 3.406 & $\mathrm{AB}$ \\
\hline & 13 Years & 28 & 57.589 & 2.681 & $\mathrm{AB}$ \\
\hline & 14 Years & 22 & 59.273 & 4.910 & B \\
\hline
\end{tabular}

For males: $\mathrm{F}-$ value $=21.18 ; p$-value $=0.000 ; \mathrm{S}(p \leq 0.05)$. For females: $\mathrm{F}$-value $=3.11 ; p-$ value $=0.030 ; \mathrm{S}(p \leq 0.05) . *$ Means with the same letters were statistically not significant.

Table (4): Analysis of variance and Duncan's Multiple Range Test of Prn-Prn 'variable for the four age groups

\begin{tabular}{|c|c|c|c|c|c|}
\hline Sex & Age Group & Number & Mean & $+\mathrm{SD}$ & Duncan's Grouping* \\
\hline \multirow{4}{*}{$\frac{\frac{0}{\sigma}}{\Sigma}$} & 11 Years & 23 & 25.348 & 2.171 & $\mathrm{~A}$ \\
\hline & 12 Years & 19 & 25.711 & 2.578 & A \\
\hline & 13 Years & 22 & 27.273 & 2.975 & $\mathrm{AB}$ \\
\hline & 14 Years & 22 & 29.227 & 3.436 & B \\
\hline \multirow{4}{*}{ 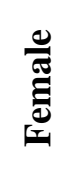 } & 11 Years & 25 & 25.940 & 2.563 & $\bar{A}$ \\
\hline & 12 Years & 22 & 26.773 & 2.477 & A \\
\hline & 13 Years & 28 & 27.571 & 1.568 & $\mathrm{AB}$ \\
\hline & 14 Years & 22 & 29.250 & 2.751 & B \\
\hline
\end{tabular}

For males: $\mathrm{F}$-value $=8.51 ; p-$ value $=0.000 ; \mathrm{S}(p \leq 0.05)$. For females: $\mathrm{F}$-value $=8.35 ; p$-value $=0.000 ; \mathrm{S}(p \leq 0.05) . *$ Means with the same letters were statistically not significant. 
Table (5): Student's t-test for the soft tissue variables between males and females for the four age groups

\begin{tabular}{|c|c|c|c|c|c|c|c|c|}
\hline Age group & Variable & Examination & Number & Mean & \pm SD & df & $t$ - test & $p$ value \\
\hline \multirow{6}{*}{ 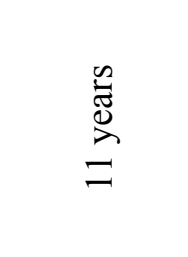 } & \multirow{2}{*}{$\mathbf{N}^{`}-\operatorname{Prn}$} & Male & 23 & 47.43 & 3.80 & & \multirow{2}{*}{-2.11} & \multirow{2}{*}{$0.040^{+}$} \\
\hline & & Female & 25 & 49.38 & 2.50 & & & \\
\hline & \multirow{2}{*}{$\mathbf{N}^{`}-\mathbf{S n}$} & Male & 23 & 54.74 & 3.15 & & \multirow{2}{*}{-2.01} & \multirow{2}{*}{$0.050^{+}$} \\
\hline & & Female & 25 & 56.38 & 2.48 & 40 & & \\
\hline & \multirow{2}{*}{ Prn - Prn` } & Male & 23 & 25.35 & 2.17 & & \multirow{2}{*}{-0.86} & \multirow{2}{*}{0.39} \\
\hline & & Female & 25 & 25.94 & 2.56 & & & \\
\hline \multirow{6}{*}{ 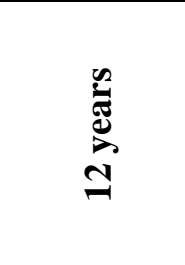 } & \multirow{2}{*}{$\mathbf{N}^{\prime}-\operatorname{Prn}$} & Male & 19 & 47.76 & 3.23 & & \multirow{2}{*}{-1.94} & \multirow{2}{*}{0.060} \\
\hline & & Female & 22 & 50.07 & 4.23 & & & \\
\hline & \multirow{2}{*}{$N^{\prime}-S n$} & Male & 19 & 55.29 & 2.58 & & \multirow{2}{*}{-1.65} & \multirow{2}{*}{0.11} \\
\hline & & Female & 22 & 56.86 & 3.41 & 39 & & \\
\hline & \multirow{2}{*}{ Prn - Prn } & Male & 19 & 25.71 & 2.58 & & \multirow{2}{*}{-1.34} & \multirow{2}{*}{0.19} \\
\hline & & Female & 22 & 26.77 & 2.48 & & & \\
\hline \multirow{6}{*}{ 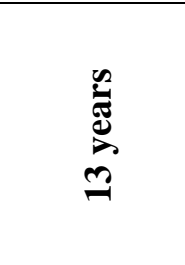 } & \multirow{2}{*}{ N`- Prn } & Male & 22 & 50.70 & 3.38 & & \multirow{2}{*}{0.07} & \multirow{2}{*}{0.95} \\
\hline & & Female & 28 & 50.64 & 3.04 & & & \\
\hline & \multirow{2}{*}{$N^{`}-\mathrm{Sn}$} & Male & 22 & 57.80 & 3.10 & & \multirow{2}{*}{0.25} & \multirow{2}{*}{0.80} \\
\hline & & Female & 28 & 57.59 & 2.68 & 48 & & \\
\hline & \multirow{2}{*}{ Prn- Prn` } & Male & 22 & 27.27 & 2.98 & & \multirow{2}{*}{-0.46} & \multirow{2}{*}{0.65} \\
\hline & & Female & 28 & 27.57 & 1.57 & & & \\
\hline \multirow{6}{*}{ 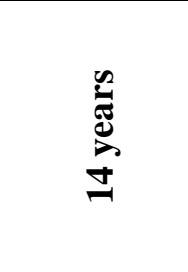 } & \multirow{2}{*}{$\mathbf{N}^{\prime}-\operatorname{Prn}$} & Male & 22 & 54.64 & 4.03 & & 125 & 019 \\
\hline & & Female & 22 & 52.91 & 4.42 & & 1.35 & 0.18 \\
\hline & & Male & 22 & 61.57 & 3.63 & & 176 & 5 \\
\hline & & Female & 22 & 59.27 & 4.91 & 42 & $1 . / 6$ & 0.085 \\
\hline & Prn - Pr & Male & 22 & 29.23 & 3.44 & & תר & 008 \\
\hline & Prn-Pr & Female & 22 & 29.25 & 2.75 & & -0.02 & 0.98 \\
\hline
\end{tabular}

Measurements in mm.; ${ }^{+}$Significant differences between males and females $(p \leq 0.05)$.

\section{DISCUSSION}

Both nose length and nose height showed higher values with increasing age group in males. At 14 years group both dimensions showed significantly higher value than 11 years group, indicating a downward and forward growth of the nose with progression of age. This coincides with the findings of Prahl-Andersen et al. ${ }^{(14)}$ who reported a gradual increase in nose length and height from 9 to 14 years in males.

In females, both dimensions showed higher values with increasing age group. At 14 years group both nose length and nose height showed significantly higher value than 11 years group. Similar findings were reported by Prahl-Andersen et al. ${ }^{(14)}$ for females from 9 to 14 years.

In comparing the values of these two dimensions for both sexes, females displayed higher values than males at 11 and 12 years groups with significance noticed at 11 years groups. Males, however, showed higher values than females at 13 and 14 years groups but with no significance. This can be explained by more nasal growth occurring in females in the early period of adolescence and this is supported by the findings of the researchers ${ }^{(12,14)}$ who showed that females experienced more nasal growth than males up to age 12 years. After this age males showed a consistent trend for greater nasal growth.

Nose depth in males demonstrated higher values with increasing age group with significant difference noticed between both 11 years, 12 years groups and 14 years group. This comes in agreement with the findings of the authors ${ }^{(12,15)}$ who demonstrated an increased nose depth in males from 11 to 14 years. Females also showed higher values for nose depth with increasing age group. Significant difference was noticed between both 11 years, 12 years groups and 14 years group. Similar findings were reported by the researchers ${ }^{(12,15)}$ for female subjects from 11 to 14 years. The comparison between males and females revealed no significant difference 
between the sexes with male values in the females in the corresponding age groups. This comes in agreement with the findings of Nanda et al. ${ }^{(12)}$ who demonstrated that from 7 to 16 years, growth curves for males and females run parallel to each other and the size of nose depth is approximately similar between the sexes, but the curves begin to diverge from age 16 to 18 years where males begin to show accelerated growth compared to the females.

\section{CONCLUSIONS}

The conclusions of this study were; males showed significantly higher values at 14 years group as compared to 11 years group for the nose length ( $\left.\mathrm{N}^{\prime}-\mathrm{Prn}\right)$, females demonstrated significantly higher valu-es at 14 years group when compared to 11 years group for $\left(\mathrm{N}^{`}-\mathrm{Prn}\right)$, nose height $\left(\mathrm{N}^{\prime}-\mathrm{Sn}\right)$ and nose depth (Prn - Prn'), females demonstrated significantly higher values at 14 years group when compared to 11 years group for $\left(\mathrm{N}^{\prime}-\mathrm{Prn}\right),\left(\mathrm{N}^{\prime}-\mathrm{Sn}\right)$ and $(\operatorname{Prn}-$ Prn'). Females also showed larger $\left(\mathrm{N}^{\prime}-\mathrm{Prn}\right)$ and $\left(\mathrm{N}^{\prime}-\mathrm{Sn}\right)$ than males at 11 years and 12 years groups with significance noticed at 11 years group, indicating greater nasal growth in females than males.

\section{REFERENCES}

1. Sarver DM, Proffit WR, Ackerman JL. Diagnosis and treatment planning in orthodontics. In: Graber TM, Vanarsdall JrRL (eds): Orthodontics: Current Principles and Technique. $3^{\text {rd }}$ ed. Mosby. 2000; Pp: 53-54, 88-89.

2. Proffit WR. Contemporary Orthodontics. $3^{\text {rd }}$ ed. Mosby. 2000; Pp: 30, 40-42, $161,171$.

3. Moseling KP, Woods MG. Lip curve changes in females with premolar extraction or non extraction treatment. Angle Orthod. 2004; 74(1): 51-62.

4. Basciftci F, Uysal T, Buyukerkmen A. Determination of Holdaway soft tissue norms in Anatolian Turkish adults. Am J Orthod Dentofac Orthop. 2003; 123(4): four age groups approximating those for 395-400.

5. Genecov JS, Sinclair PM, Dechow PC. Development of the nose and soft tissue profile. Angle Orthod. 1990; 60(3): 191198.

6. Foley TF, Duncan PG. Soft tissue profile changes in late adolescent males. Angle Orthod. 1997; 67(5): 373-380.

7. Bishara SE, Jorgensen GJ, Jackobsen JR. Changes in facial dimensions assessed from lateral and frontal photographs. Part I: Methodology. Am J Orthod Dentofac Orthop. 1995; 108(4): 389-393.

8. Nanda RS. The contributions of craniofacial growth to clinical orthodontics. Am J Orthod Dentofac Orthop. 2000; 117(5): 553-555.

9. Akgul AA, Toygar TU. Natural craniofacial changes in the third decade of life: A longitudinal study. Am J Orthod Dentofac Orthop. 2002; 122(5): 512-522.

10. Formby WA, Nanda RS, Currier GF. Longitudinal changes in adult facial profile. Am J Orthod Dentofac Orthop. 1994; 105(5): 464-476.

11. Kerr WJ. A longitudinal cephalometric study of dentofacial growth from 5 to 15 years. Br J Orthod. 1979; 6: 115-121.

12. Nanda R, Meng H, Kapila S, Goorhuis J. Growth changes in the soft tissue facial profile. Angle Orthod. 1990; 60(3): 177190.

13. Axelsson S, Kjaer I, Bjornland T, Storhaug K. Longitudinal cephalometric standards for the neurocranium in Norwegians from 6 to 21 years of age. Eur $J$ Orthod. 2003; 25: 185-198.

14. Prahl-Andersen B, Ligthelm-Bakker A, Wattel E, Nanda K. Adolescent growth changes in soft tissue profile. Am J orthod Dentofac Orthop. 1995; 107(5): 476-483.

15. Meng H, Goorhuis J, Kapila S, Nanda R. Growth changes in the nasal profile from 7 to 18 years of age. Am J Orthod Dentofac Orthop. 1988; 94(4): 317-3. 